\title{
Educação ambiental como ferramenta integradora entre escola/aluno/graduandos
}

\section{Environmental education as an integrating tool between school / student / graduants}

\author{
Isabelle Maria Magalhães PAIVA ${ }^{1}$; Tamires Rayane da Silva ALVES²; Vanessa de Souza \\ FARIAS $^{3}$; Henrique Rodrigues SILVA ${ }^{4}$; Rubens Pessoa BARROS ${ }^{5}$ \\ ${ }^{1}$ Graduanda do Curso de Ciências Biológicas pela Universidade Estadual de Alagoas, Arapiraca, Alagoas. E- \\ mail: isabelle.paiva3105@gmail.com; ${ }^{2-4}$ Graduando (a) do Curso de Ciências Biológicas pela Universidade \\ Estadual de Alagoas; ${ }^{5}$ Doutor em Proteção de Plantas pelo Centro de Ciências Agrárias - UFAL.
}

E-mail do autor (a) correspondente: isabelle.paiva3105@gmail.com

Resumo - A implantação da educação ambiental nas escolas pode ser considerada uma das formas mais eficazes para conquistar uma sociedade sustentável, pois é no ambiente escolar que os futuros cidadãos recebem os primeiros estímulos para a conscientização sobre o meio ambiente, com a criação do jardim/horta escolar torna-se possível o desenvolvimento do processo de ensino-aprendizagem, por meio da prática, além de despertar valores sociais como participação, relação interpessoal, senso de responsabilidade e sensibilização quanto às questões relacionadas ao meio ambiente. $\mathrm{O}$ objetivo principal do projeto de educação ambiental visou promover mudança comportamental dos alunos, com a formação de uma nova visão sobre a importância e cuidado com o meio ambiente. $\mathrm{O}$ presente projeto foi desenvolvido por graduandos do Curso de Licenciatura em Ciências Biológicas da Universidade Estadual de Alagoas - UNEAL, Campus I, na Escola de Ensino Fundamental Maria de Nazaré, situada no município de Arapiraca-AL. A metodologia do trabalho seguiu várias etapas predeterminadas como, por exemplo, aulas, dinâmicas e a construção de um jardim/horta escolar, todos os encontros com duração de 2 horas, durante 10 dias. Com isto, verificou-se que os trabalhos desenvolvidos na sala de aula e no jardim/horta criaram a percepção da solidariedade, fundamental para trabalhar em grupo, contribuindo positivamente para a construção de atos sustentáveis não só na escola, mas sim em toda comunidade, assim a educação ambiental no ambiente escolar pode ser utilizada como uma ferramenta eficaz na formação integral do estudante.

Palavras-chave: Reciclagem. Práticas pedagógicas. Meio Ambiente. Ambiente escolar.

ABSTRACT: The implementation of environmental education in schools can be considered one of the most effective ways to achieve a sustainable society, because it is in the school environment that the future citizens receive the first stimuli to raise awareness about the environment, with the creation of the garden / school garden it becomes possible to develop the teaching-learning process through practice, as well as to awaken social values such as participation, interpersonal relationship, sense of responsibility and awareness of issues related to the environment. The main objective of the environmental education project was to promote the behavioral change of the students, with the formation of a new vision about importance and care with the environment. This project was developed by undergraduates of the Biological Sciences Degree Program of the State University of Alagoas - UNEAL, Campus I, at the Maria de Nazaré Elementary School, located in the municipality of Arapiraca-AL. The methodology of the work followed several predetermined steps, such as classes, dynamics and the construction of a garden / school garden, all meetings lasting 2 hours for 10 days. With this, it was verified that the work developed in the classroom and in the garden created the perception of solidarity, fundamental to work in a group, contributing 
positively to the construction of sustainable acts not only in the school, but in every community, environmental education in the school environment can be used as an effective tool in the integral formation of the studen

Keys-words: Recycling. Pedagogical practices. Environment. School environment.

\section{Introdução}

A escola é um espaço considerado para estabelecer trocas e informações, um eventual lugar que incentivem os alunos a terem ideias e postura de cidadãos cientes de suas responsabilidades e, fundamentalmente, integrantes do meio ambiente (CUBA, 2010).

As práticas de Educação Ambiental nas escolas estão fundamentadas na construção de sociedades justas e sustentáveis, nos valores da liberdade, igualdade, solidariedade, democracia, justiça social, responsabilidade, sustentabilidade e educação como direito de todos e todas. No entanto o conhecimento tem mais valor quando construído coletivamente, no qual acontece uma troca de saberes, com que sabemos e o que aprendemos. É com esta construção coletiva que o ensino deve se preocupar mais. (MEDEIROS et al., 2011).

A sensibilização sobre as questões ambientais coube à escola o papel primordial de ser a facilitadora do acesso por parte dos educandos aos conhecimentos necessários para a sua construção enquanto sujeito atuante, construtor e modificador da realidade social, ou seja, de sua cidadania, então ao profissional da educação cabe um papel primordial nesse processo. No caminho do efetivar a educação ambiental, ao professor incumbe a tarefa essencial de apontar o trajeto aos alunos, criar situações em que estes hajam de forma construtiva de modo a desenvolverem competências e habilidades, e possam refletir de forma crítica sobre a realidade de modo a adquirirem a consciência da necessidade da conservação ambiental (AGUIAR et al., 2017).

Diante de uma sociedade consumista, que consequentemente gera uma imensa quantidade de resíduos, a sensibilização ambiental da população é de suma importância. Reciclar materiais a partir da reutilização de sua matéria-prima para fabricar novos produtos diminuindo assim a extração de recursos naturais (SILVA et al., 2004).

No Brasil, cerca de 42,6 milhões de toneladas de resíduos sólidos, ou 58,7\% do coletado, seguem para aterros sanitários. Por outro lado, também se tem o registro do aumento do volume de resíduos enviados para destinação inadequada, com quase 30 milhões de toneladas de resíduos dispostos em lixões ou aterros controlados, que não possuem o conjunto de sistemas e medidas necessárias para a proteção do meio ambiente contra danos e degradações (ABRELPE, 2018).

A construção de objetos, utilizando resíduos ou reciclando, é uma maneira criativa de colaborar com a sensibilização ambiental, podendo criar ambientes que harmonizam com os elementos naturais, como por exemplo, hortas e jardins suspensos. (VENTURA et al., 2018).

A reciclagem é um conjunto de técnicas de reaproveitamento de materiais descartados; reintroduzindo-os no ciclo produtivo. É uma das alternativas de tratamento de resíduos sólidos mais vantajosas. Tanto do ponto de vista ambiental quanto do social: ele reduz o consumo de recursos naturais, poupa energia, diminui o volume de lixo e emprega milhares de pessoas. É um processo industrial que começa em casa (MMA, 2018).

Nesse contexto, o projeto horta escolar torna possível o desenvolvimento do processo de ensino-aprendizagem, por meio da prática, além de despertar valores sociais como participação, relação interpessoal, senso de responsabilidade e sensibilização quanto às questões relacionadas ao meio ambiente. Os alunos se tornaram capazes de analisar e discutir 
as melhores formas para manter um ambiente saudável, além de obterem um cuidado maior com a alimentação e a higiene (PEREIRA et al, 2012).

A horta escolar permite relacionar a educação ambiental com educação alimentar e valores sociais, tornando possível a participação dos sujeitos envolvidos, desenvolvendo uma sociedade sustentável através de atividades voltadas para Educação Ambiental. Educação Ambiental deve ser tratada a partir de uma matriz que conceba a educação como elemento de transformação social apoiada no diálogo e no exercício da cidadania. Comportamentos ambientalmente "corretos" como, por exemplo, coleta seletiva, reutilização de garrafas de politeleftalato de etileno - PET, devem ser aprendidos na prática, no cotidiano da vida escolar, contribuindo para a formação de cidadãos responsáveis (CRIBB, 2010; RODRIGUES; FREIXO, 2009).

A horta escolar pode se tornar um instrumento facilitador do trabalho dos temas transversais, em especial dos seguintes: Meio Ambiente, Saúde, Trabalho e Consumo. Além disso, a horta pode também se tornar um ambiente integrador da comunidade escolar e instrumento para o ensino das diferentes disciplinas do ensino fundamental, propiciando atividades práticas e prazerosas a alunos, professores, funcionários e famílias (FROES et al., 2015).

Segundo Dias; Leal; Carpi Junior (2016) "trabalhar com educação ambiental significa pensar num futuro melhor para nosso mundo e para as pessoas que aqui vivem, colocando em prática uma ação transformadora das nossas consciências e de nossa qualidade de vida".

Portanto, o projeto de educação ambiental tem como objetivo promover mudança comportamental dos alunos, com a formação de uma nova visão sobre a importância e cuidado com o meio ambiente, através das aulas durante o projeto e a construção do jardim/horta, onde os alunos colocarão em prática os conceitos sustentabilidade, preservação e conservação.

\section{Metodologia}

O projeto de Educação Ambiental foi implantado na Escola de Ensino Fundamental Maria de Nazaré, localizada no Bairro São Luiz I, município de Arapiraca. Nesse trabalho foram envolvidos todos os alunos do $7^{\circ}$ ano " $\mathrm{C}$ ", onde participaram de forma efetiva de atividades realizadas em 10 encontros, sendo estes de 2 horas cada, tendo início no dia 10 de Setembro de 2018 até o dia 20 de Novembro de 2018.

O projeto foi divido em duas etapas, a primeira etapa ocorreu em sala, abordando os seguintes temas: a importância do cuidado com o meio ambiente, a comemoração do dia da árvore, as consequências do lixo no planeta utilizando o filme $\mathrm{O}$ Wall-e, a importância da reciclagem e destinação correta do lixo, ocorrendo dinâmicas em cada encontro após a explicação dos assuntos em sala de aula, com o intuito de fazer com que o aluno absorva melhor o conteúdo visto. Após os alunos entenderem sobre a importância de cada tema, a segunda etapa foi destinada apenas para a confecção dos materiais para o jardim/horta e posteriormente a construção e plantação.

\section{Resultados e discussão}

Com o desenvolvimento do projeto, os alunos puderam ser apresentados ao real conceito de sustentabilidade, através das aulas e dinâmicas que ocorreram durante o projeto e da construção do jardim/horta, podendo então aprender sobre a importância do meio ambiente e de se preservar onde vivemos. 


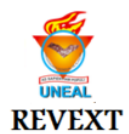

Revista de Extensão da Uneal $\bigcap \ni £ U$ ISSN 2447-2751

Vol. 4, no 1. 2019, Julho de 2019.

Durante a conversação sobre a temática meio ambiente no primeiro encontro, foi analisado que a maioria dos alunos tinha noção sobre o que é o meio ambiente, quais os problemas ambientais que existem e o que pode ser feito para diminuir os índices desses problemas. Com isso, ocorreu uma aula expositiva com o auxilio do Datashow, onde foi exposto os problemas ambientais, quais as atitudes devemos tomar para solucionais tais problemas, quando é comemorado o dia meio ambiente e após as explicações ocorreu a dinâmica "complete a frase" onde cada aluno teve a oportunidade de falar sobre a frase que recebeu e completar com uma mensagem de apoio ao meio ambiente.

No encontro seguinte, ocorreu o primeiro contato dos alunos com o ambiente natural aconteceu durante oficina dia da árvore (Figura 1), onde os alunos puderam plantar mudas de jasmim (Jasminum) (Figura A) e pau-brasil (Caesalpinia Echinata) (Figura B), conhecer sobre a importância do dia da árvore, quais as árvores que representam o Brasil, também houve a confecção de placas para colocar em cada árvore com o intuito de chamar a atenção da comunidade escolar para o cuidado com as árvores (Figura C), posteriormente, já em sala, os alunos participaram da dinâmica "árvore das promessas" (Figura D), onde cada aluno fez sua promessa a respeito do meio ambiente e em seguida foi passado um vídeo educativo sobre A árvore que não queria morrer e através dele houve uma conversação a respeito da importância da árvore.

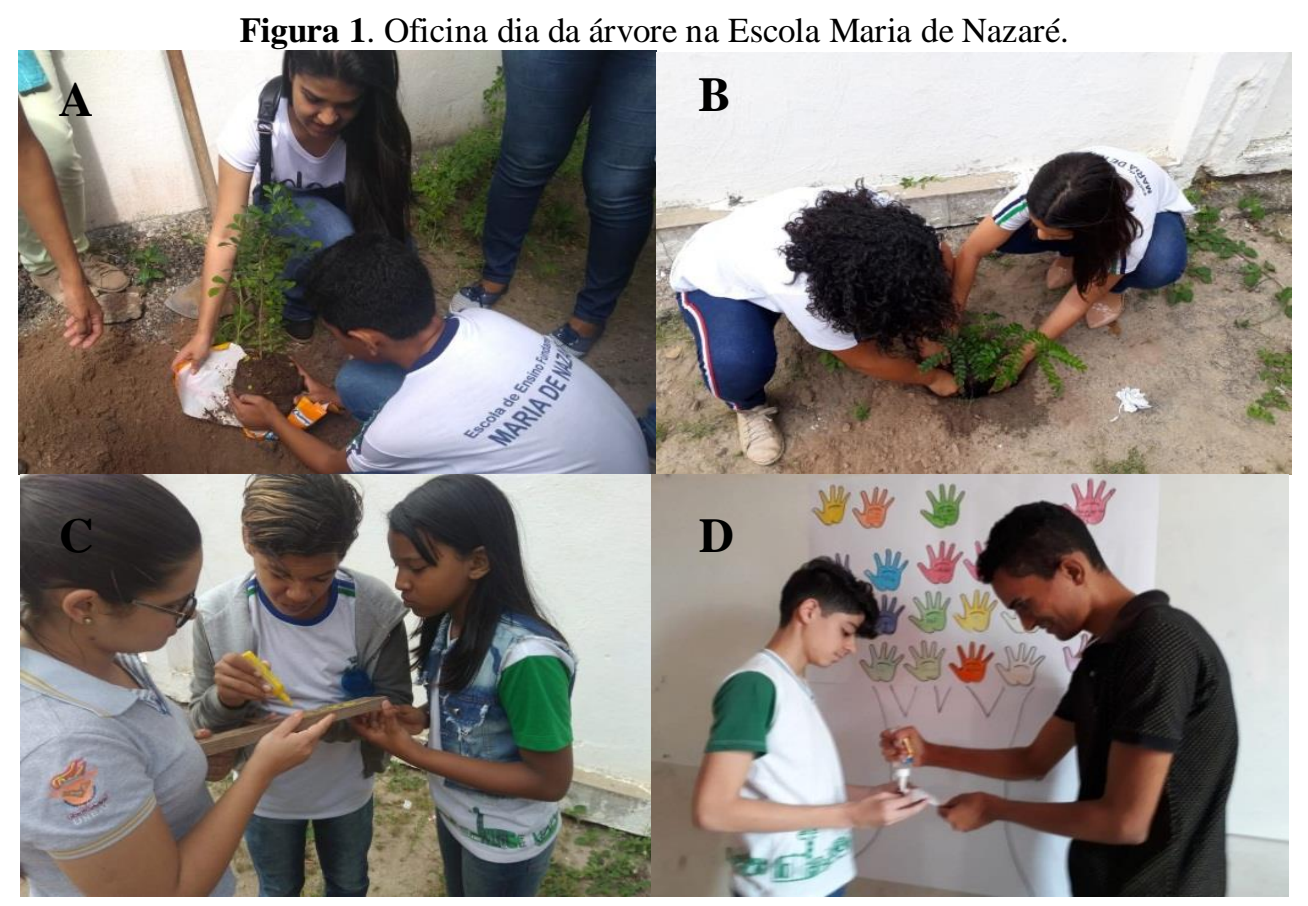

Fonte: Graduandos de Ciências Biológicas/UNEAL, 2018.

Para abordar a temática reciclagem, foi utilizado o filme O Wall-e (2008), uma animação da Disney e da Pixar, cujo roteiro do filme aborda vários aspectos que puderam ser trabalhados em sala, entre eles o acúmulo de lixo no planeta e as consequências dessas atitudes para nós seres humanos. Após o filme, houve uma roda de conversa onde os alunos puderam expor suas opiniões relacionadas ao que foi visto durante o filme, falando também sobre algumas cenas que mais chamaram a sua atenção e em seguida fizeram um desenho sobre o que eles desejam para o futuro (Figura 2). 
Figura 2. Desenhos dos alunos sobre o que eles desejam para o futuro.

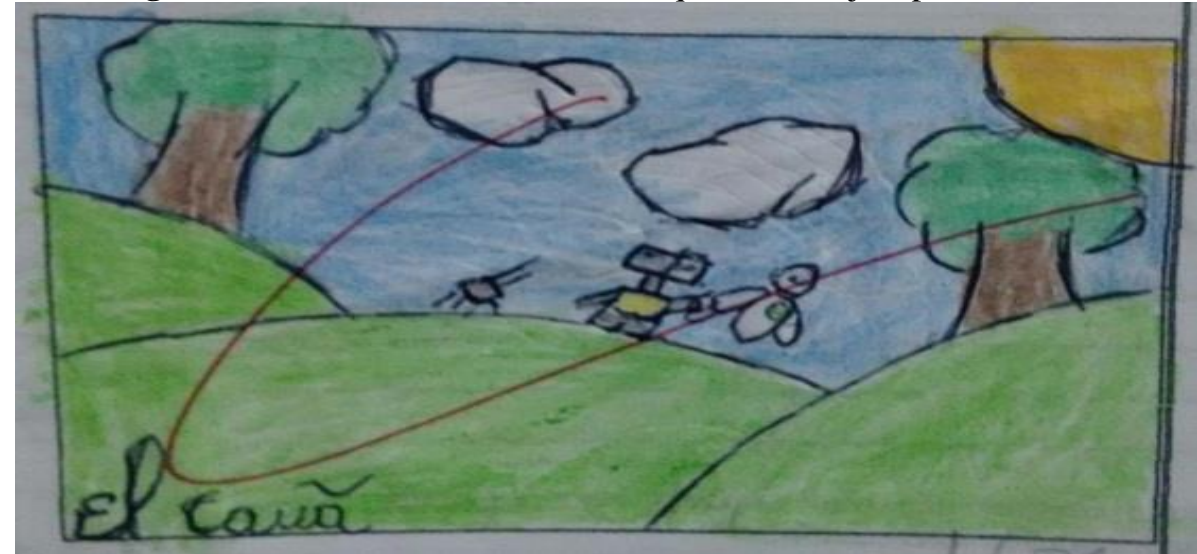

Fonte: Graduandos de Ciências Biológicas/UNEAL, 2018.

A aula do encontro seguinte foi voltada para as questões da temática: o lixo no meio ambiente (Figura 3), acontecendo então uma aula expositiva sobre a origem do lixo, onde os alunos puderam compreender as classificações e destinação para cada tipo de lixo, a consequência da destinação errada, onde muitos alunos expuseram opiniões sobre tais consequências, também foi visto as doenças que o lixo traz para nós seres humanos e a importância da coleta seletiva (Figura A), após a conversação ocorreu à dinâmica "lixo na lixeira correta", onde cada aluno pôde colocar em prática o que foi visto anteriormente (Figura B) e (Figura C), após todos alunos colarem as figuras nos devidos lixeiro, houve uma conversação sobre como seria a reciclagem dos lixos que foram representados pelas figuras (Figura D).

Figura 3. Dinâmica lixo na lixeira correta na Escola Maria de Nazaré.

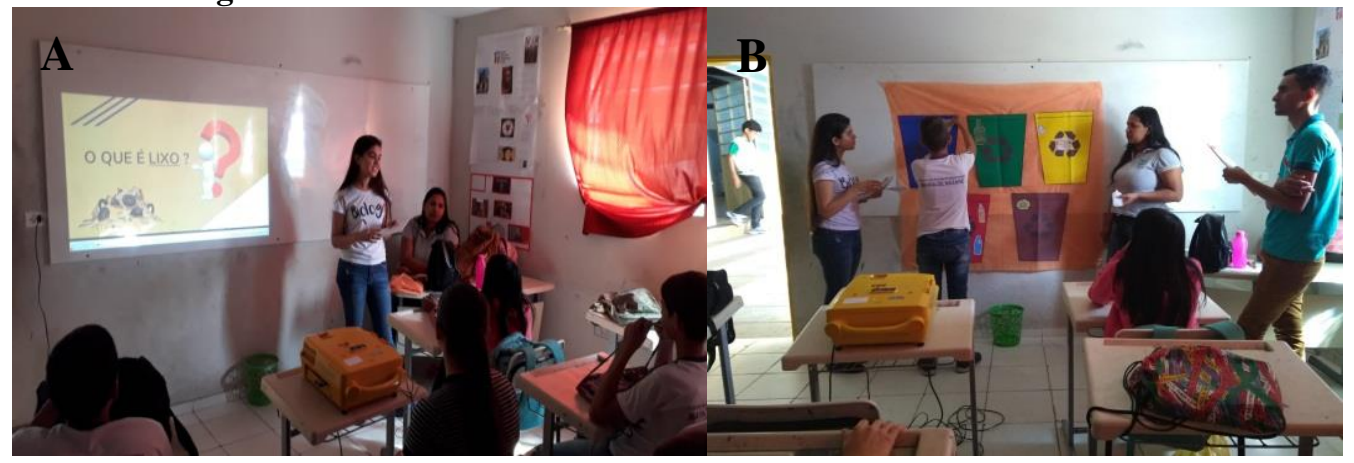




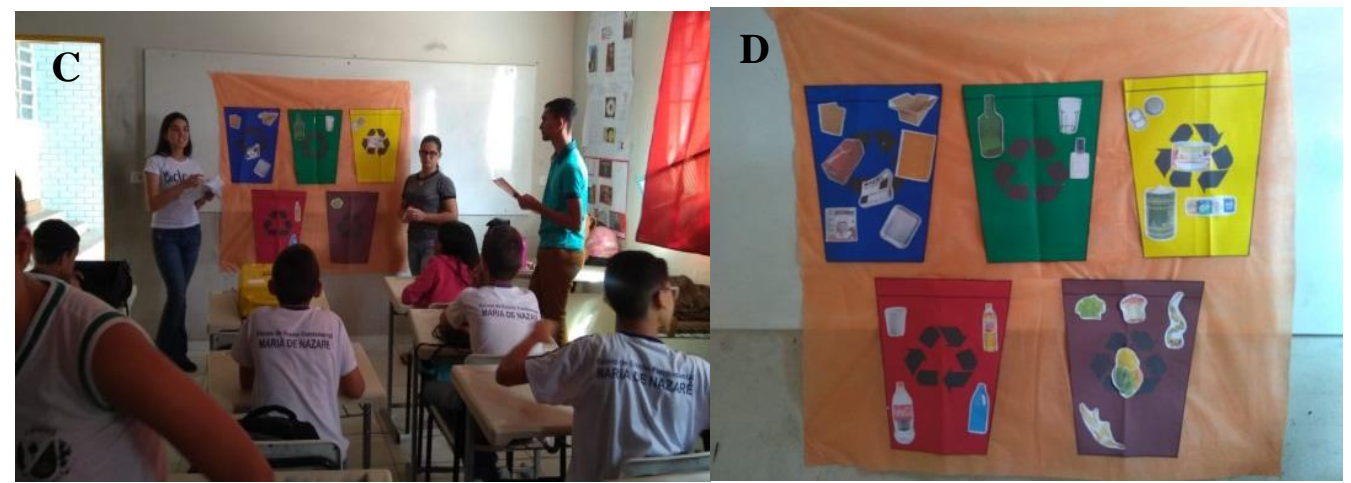

Fonte: Graduandos de Ciências Biológicas/UNEAL, 2018.

Após os alunos entenderem sobre a importância do cuidado com o meio ambiente e a importância de adquirirmos hábitos conscientes através da preservação e reciclagem, os alunos foram reconectados com o ambiente natural para dar início à construção do jardim/horta e perceberam que é responsabilidade de cada individuo criar um mundo sustentável para as futuras gerações, além de desenvolver habilidades para trabalhar em equipe, melhorando a socialização dos mesmos. Os alunos foram divididos em quatro equipes para a confecção dos materiais para a construção do jardim/horta (Figura 4). A primeira e segunda equipe ficou responsável pela confecção das placas (Figura A), a terceira equipe ficou responsável por recortar as garrafas pets e decorar as latas usadas no jardim (Figura B), a quarta equipe ficou responsável por confeccionar flores reutilizando calotas de pneu de carro (Figura C), após a confecção das placas, os alunos puderam coloca-las nas árvores (Figura D).

Figura 4. Confecção dos materiais para o jardim/horta na escola Maria de Nazaré.

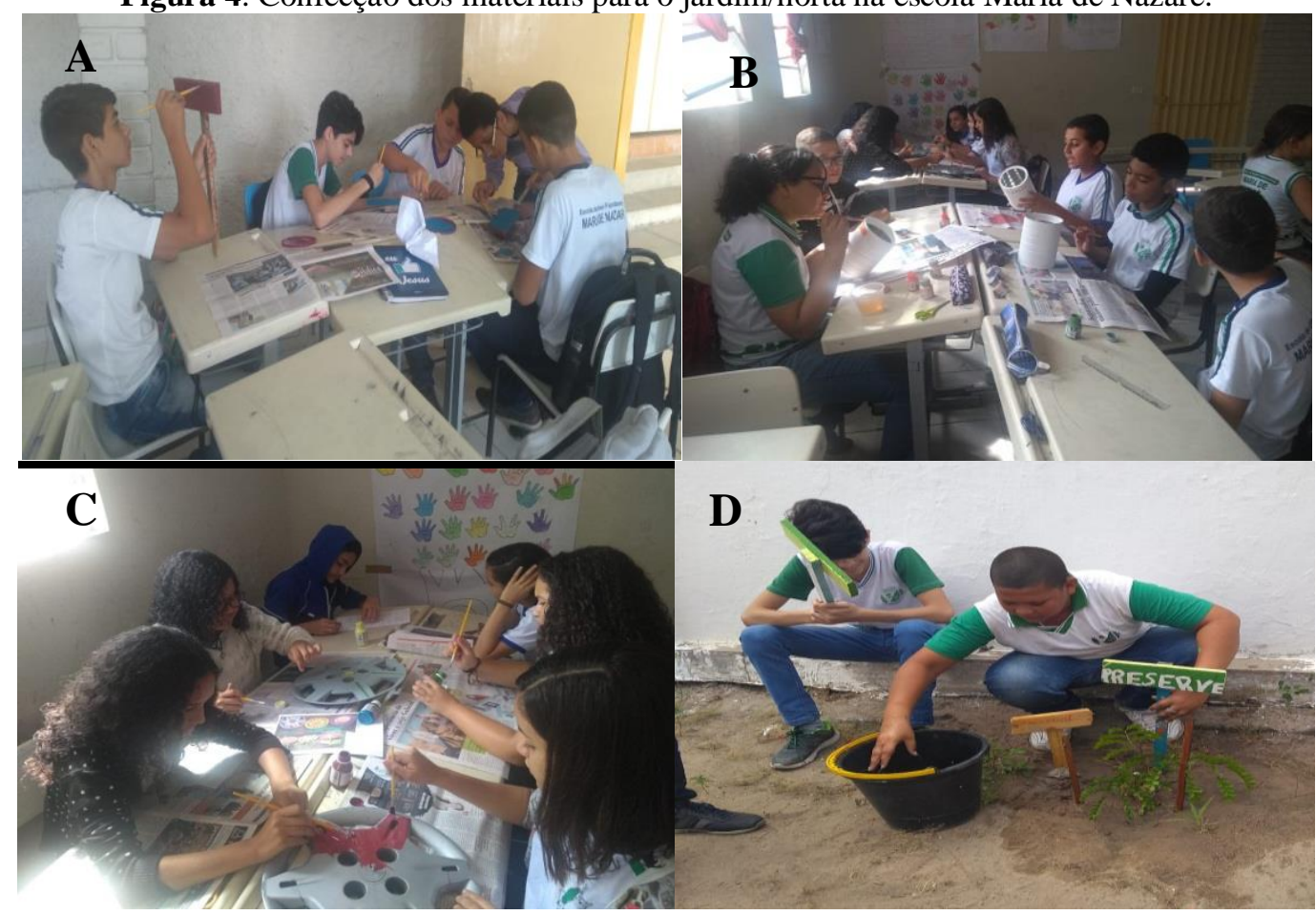

Fonte: Graduandos de Ciências Biológicas/UNEAL, 2018.

Assim, após a confecção dos materiais, ocorreu à construção do jardim/horta em dois encontros, com isso a turma foi divida em dois grupos, o primeiro grupo de alunos foram os 
responsáveis pela jardinagem (Figura 5), durante o encontro os alunos confeccionaram o jardim térreo (Figura A) e (Figura B) e em seguida o jardim vertical (Figura C) e (Figura D), e em seguida receberam orientação de como cuidar de cada planta, os alunos foram divididos para que alguns pudessem organizar os materiais e o restante pudesse plantar e regar as mudas.

Figura 5. Primeiro dia da confecção do jardim/horta na escola Maria de Nazaré.

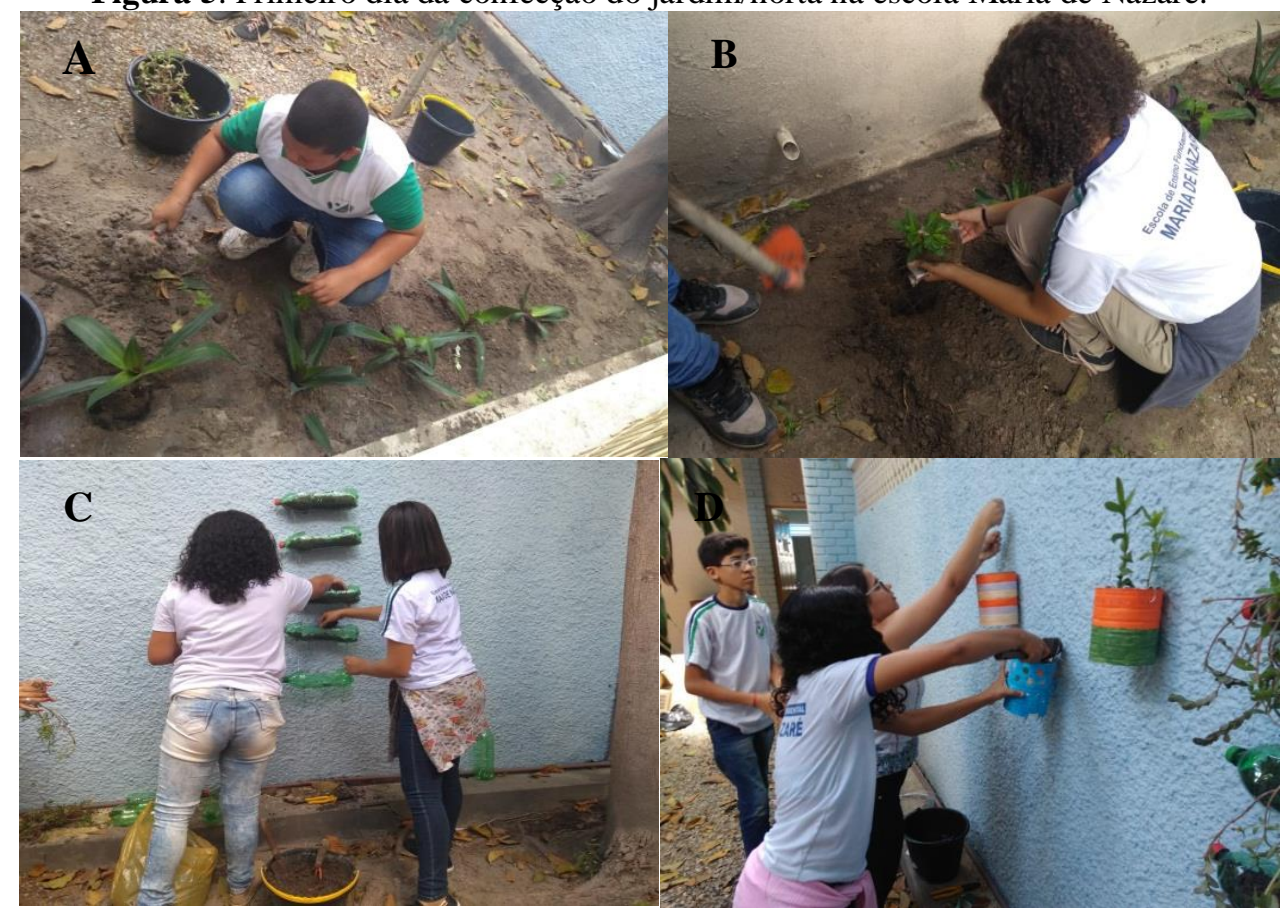

Fonte: Graduandos de Ciências Biológicas/UNEAL, 2018.

O segundo encontro aconteceu com o grupo, que foram os responsáveis pela construção da horta e retoques finais do jardim/horta (Figura 6). Durante a construção alguns alunos ficaram responsáveis por pintar algumas embalagens que foram reutilizadas para plantar couve e tomate (Figura A), e em seguida foram plantadas as hortaliças e plantas medicinais (Figura B). As espécies de hortaliças cultivadas foram: alface (Lactuca sativa L.); couve-manteiga (Brassica oleracea Var. acephala); couve-brocoli (Brassica oleracea var. itálica); pepino (Cucumber marketmore); tomate (Solanum lycopersicum); pimenta (Capsicum spp); cebolinha-de-cheiro (Allium fistulosum L.); coentro (Coriandrum sativum L.); As espécies de plantas medicinais cultivadas foram: hortelã (Mentha spp.); manjericão (Ocimum basilicum L.); alecrim (Rosmarinus officinalis); capim santo (Cymbopogon citratus). Durante a plantação os alunos puderam conhecer sobre o beneficio de cada hortaliça 


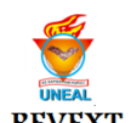

eduneal

Revista de Extensão da Uneal $\bigcap \ni £ \cup$ ISSN 2447-2751

Vol. 4, no 1. 2019, Julho de 2019.

e das plantas medicinais, ressaltando que o uso das ervas medicinais é para enfermidades de baixa gravidade. As (Figura C) e (Figura D) representam o resultado final do jardim/horta.

Figura 6. Segundo dia da confecção do jardim/horta na Escola Maria de Nazaré.

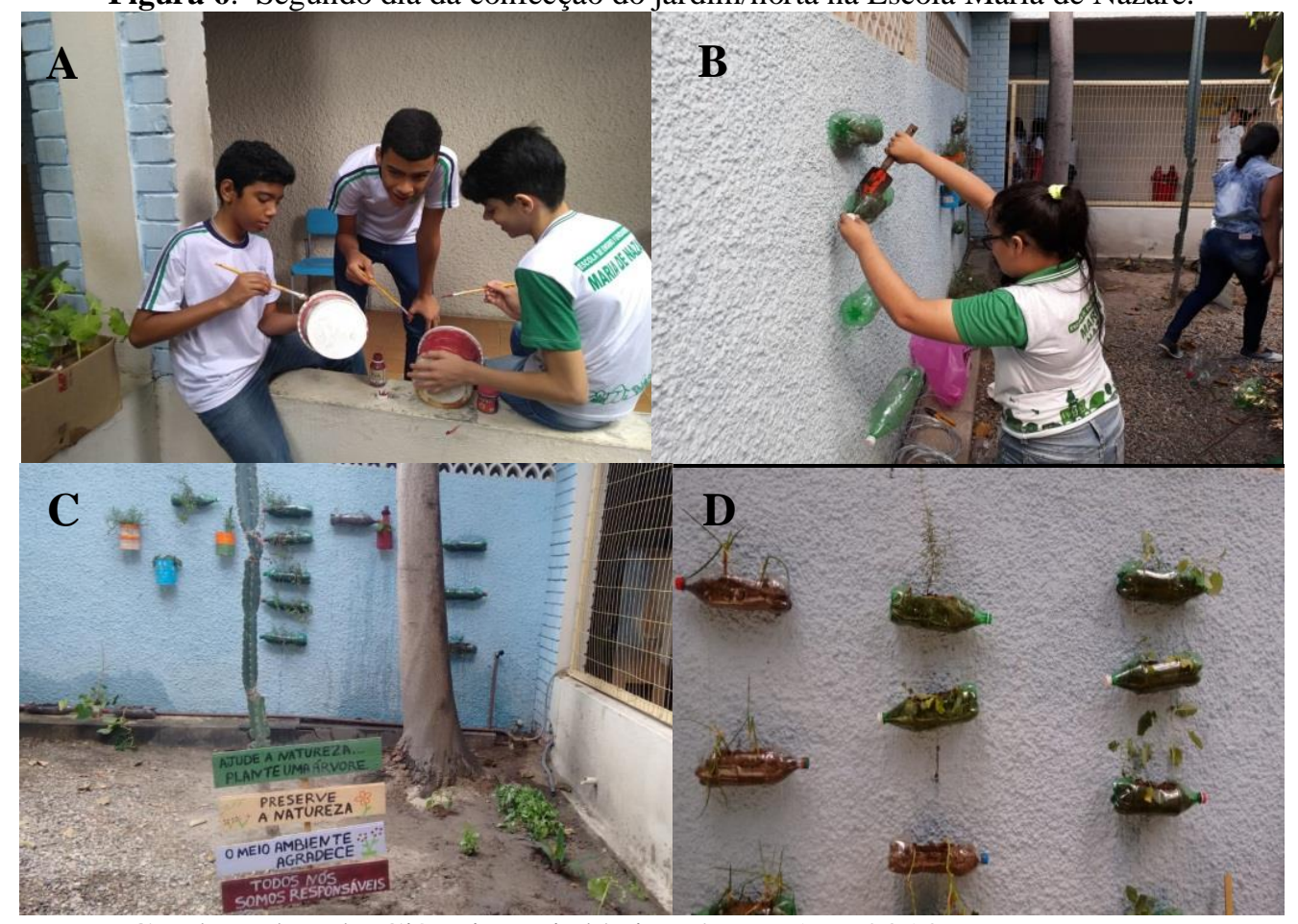

Fonte: Graduandos de Ciências Biológicas/UNEAL, 2018.

No encontro seguinte ocorreram atividades sobre todo o conteúdo visto durante projeto (Figura 7), cada aluno recebeu um caça-palavras e perguntas sobre os conteúdos e, cada resposta estava embaralhada no caça-palavras.

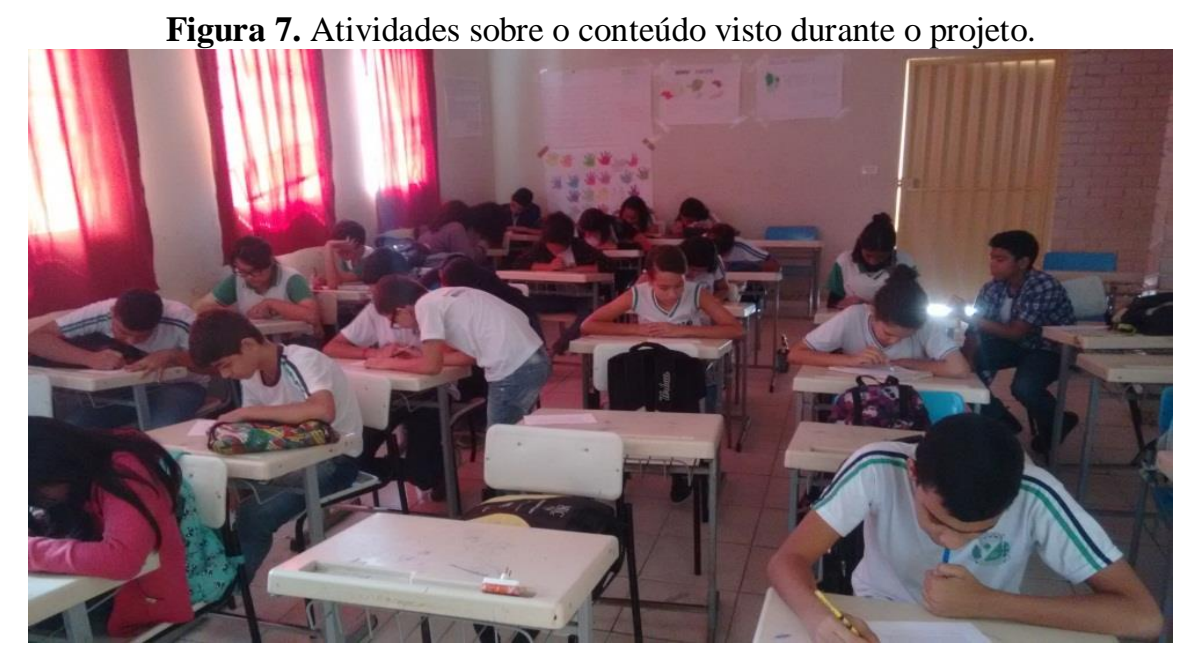

Fonte: Graduandos de Ciências Biológicas/UNEAL, 2018.

Em seguida, todos os alunos receberam três perguntas sobre o projeto, onde eles puderam expor suas opiniões sobre ter participado do projeto de Educação Ambiental, após 
todos responderam as perguntas, houve uma roda de conversa para que cada aluno pudesse falar sobre as suas respostas. Todas as respostas foram positivas nas três questões, demonstrando o quanto é importância ter um projeto de Educação Ambiental na escola.

A primeira pergunta foi sobre o que eles acharam do projeto de Educação Ambiental na sua escola, foram selecionadas algumas respostas:

"Divertido. Por ter experiência com as plantas." natureza."

"Eu achei o projeto muito produtivo. Ele ensinou a importância de preservar a diferente."

"Legal. Porque é muito bom ajudar o meio ambiente e também é uma atividade

"Eu amei, foi ótimo. Aprender e estudar é bom, se fosse desse jeito todas as aulas, por mim, seria bom. Vou sentir saudades."

"Eu achei legal, porque aprendemos como plantar, coisa que eu não sabia."

"Muito bom, porque ensinou muita coisa de um jeito legal."

A segunda pergunta foi sobre o que eles aprenderam durante o projeto, as respostas selecionadas foram as seguintes:

"Que devemos cuidar do Meio Ambiente e protegê-lo"

"A preservar o Meio Ambiente, cuidar e plantar."

"Que é importante preservar e cuidar da natureza e do planeta."

"Aprendi como plantar, cuidar e do quê as plantas precisam para viver."

"Que cuidar da natureza é essencial."

E a terceira e ultima pergunta teve o intuito de saber se eles acham importante estudar sobre o meio ambiente através de projetos como esse, as respostas selecionadas foram as seguintes:

"Sim. Porque a gente aprende muita coisa através desses projetos."

"Sim. Porque as pessoas aprendem a preservar o meio ambiente."

"Sim. As pessoas aprendem mais com o projeto."

"Sim. Porque sobre o meio ambiente temos que aprender muita coisa."

"Sim. Faz as pessoas se conectar com o ambiente, cuidar dele e conhecer."

No ultimo encontro aconteceu à entrega de certificado para os alunos, em seguida foram citados os nomes dos alunos que mais se destacaram durante o projeto e os mesmos ficaram responsáveis por incentivar o restante da turma a dar continuidade aos cuidados do jardim/horta (Figura 8).

Figura 8. Entrega de certificado aos alunos do $7^{\circ}$ ano "C".

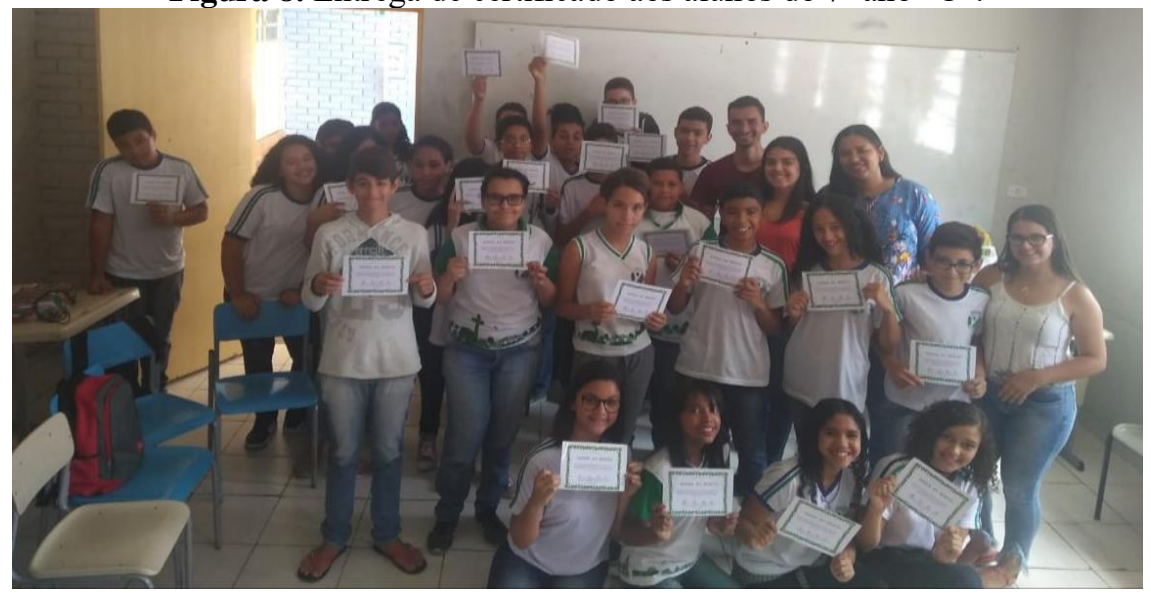

Fonte: Graduandos de Ciências Biológicas/UNEAL, 2018. 


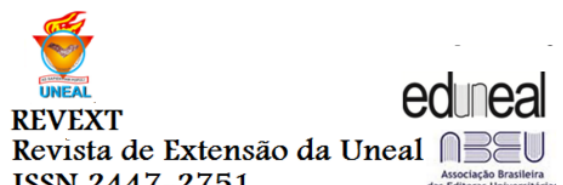

ISSN 2447-2751

Vol. 4, no 1. 2019, Julho de 2019.

\section{Conclusão}

Este trabalho reforça a importância de estimular ações junto às escolas para que desde a infância seja incentivado o respeito ao meio ambiente, estabelecendo relações saudáveis com a natureza e entre as pessoas, para que se formem cidadãos capazes de assumir novas atitudes em relação à busca de soluções para os problemas sociais e ambientais. Assim, as atividades desenvolvidas nas aulas contribuíram para conscientizar os alunos acerca da temática ambiental, levando-os a um interesse maior no conhecimento e nas relações estabelecidas com o meio ambiente através das aulas, da experiência com o jardim/horta e, também permitiu que compreendessem a importância das hortaliças e plantas medicinais para a saúde humana. Quando um jovem se envolve no processo de cuidar do meio ambiente, através da criação do jardim/horta, ele passa por uma experiência que traz responsabilidade e orgulho por conseguir executar as etapas. Dessa forma, o projeto alcançou as expectativas, demonstrando que é possível, preservar o meio ambiente, através de técnicas simples como a reciclagem e o plantio do jardim/horta.

\section{Referencias}

ABRELP - Associação Brasileira de Empresas de Limpeza Pública e Resíduos Especiais. Panorama dos resíduos sólidos no Brasil. Disponível em: < http://abrelpe.org.br/panorama/> Acesso em 20 out. 2018.

AGUIAR, P.C.B. et al. Da Teoria À Prática Em Educação Ambiental. Revista

Gestão \& Sustentabilidade Ambiental. v. 6, n. 3, 2017.

CRIBB, S.L.S.P. Contribuições da Educação Ambiental e Horta Escolar na Promoção de Melhorias ao Ensino, à Saúde e ao Ambiente. Rev. Eletr. do Mestr. Profis. em Ensino, Saúde e Ambiente, Rio Grande do Sul, v. 3, n. 1, p. 42-60, jan/abr. 2010.

CUBA, Marcos Antônio. Educação Ambiental nas Escolas. ECCOM, v. 1, n. 2, p. 23-31, jul./dez., 2010. Universidade de FATEA, Lorena/SP.

FROES, E, K. et al. Hortas Escolares: Uma Proposta De Integração Da Horta Às Disciplinas Do Ensino Fundamental Nas Escolas Do Alto Vale Do Itajaí. In: MOSTRA NACIONAL DE INICIAÇÃO CIENTÍFICA E TECNOLOGIA INTERDISCIPLINAR. 8. Santa Rosa. Anais eletrônicos... Santa Rosa do Sul: Campus IFC.2015.

DIAS, L. S.; MARQUES, M. D.; DIAS L. S. Educação, educação ambiental, percepção ambiental e educomunicação. In: DIAS, L. S.; LEAL, A. C.; JUNIOR, S. C. Educação Ambiental: conceitos, metodologia e práticas. Tupã: ANAP, 2016. cap. 1, p. 12-44.

MEDEIROS, Aurélia Barbosa et al. A Importância da educação ambiental na escola nas séries iniciais. Revista Faculdade Montes Belos, v. 4, n. 1, set. 2011. 
MMA. Ministério do Meio Ambiente. Disponível em:<http://www.mma.gov.br/informma/item/7656-reciclagem> Acesso em: 13 out. 2018.

SILVA, J. I. S da. et al. Reduzir, reutilizar e reciclar - Proposta de Educação Ambiental para o Brejo Paraibano. In: CONGRESSO BRASILEIRO DE EXTENSÃO UNIVERSITÁRIA, 2, 2004, Belo Horizonte.

VENTURA, M. V. A. ; BESSA, M. M. ; ALVES, L. S. ;COSTA, E. M. Implantação e benefícios de um jardim suspenso e com pneus em um Colégio Militar em Goianésia-GO. Gl. Sci Technol, Rio Verde, v.11, n.01, 2018. 